\title{
Selective Extraction of Medium-Chain Carboxylic Acids by Electrodialysis and Phase Separation
}

\author{
Paula Andrea Hernandez, Miaomiao Zhou, Igor Vassilev, Stefano Freguia, Yang Zhang, Jürg Keller,
} Pablo Ledezma, and Bernardino Virdis*

Cite This: ACS Omega 2021, 6, 7841-7850

Read Online

\section{ACCESS | Lill Metrics \& More | 回 Article Recommendations ｜（） Supporting Information}

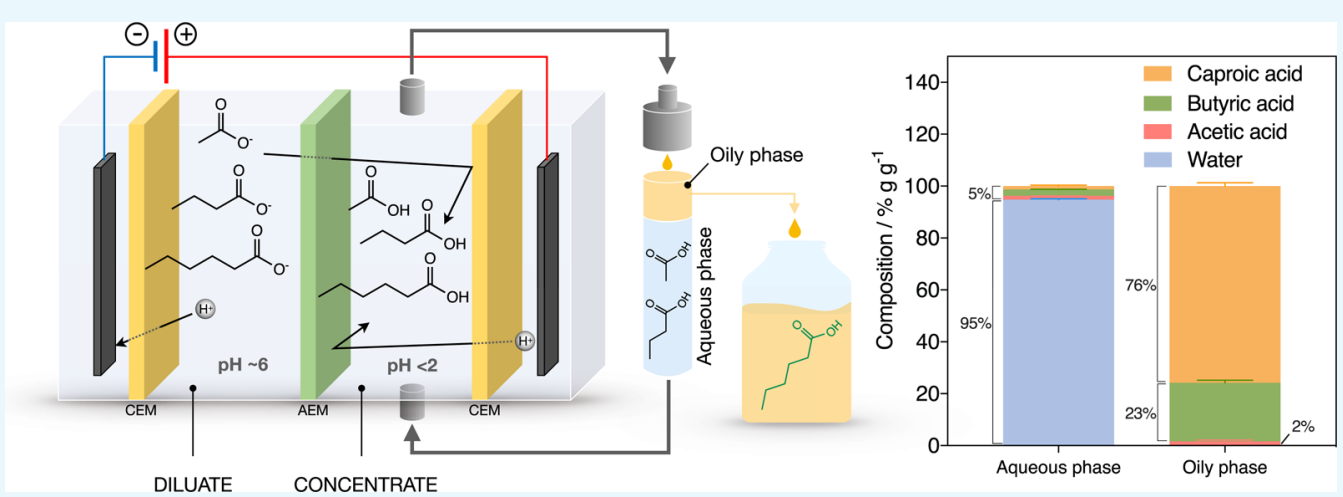

ABSTRACT: Carboxylic acids obtained via the microbial electrochemical conversion of waste gases containing carbon dioxide (i.e., microbial electrosynthesis) can be used in lieu of nonrenewable building-block chemicals in the manufacture of a variety of products. When targeting valuable medium-chain carboxylic acids such as caproic acid, electricity-driven fermentations can be limited by the accumulation of fermentation products in the culturing media, often resulting in low volumetric productivities and titers due to direct toxicity or inhibition of the biocatalyst. In this study, we tested the effectiveness of a simple electrodialysis system in upconcentrating carboxylic acids from a model solution mimicking the effluent of a microbial electrochemical system producing short- and medium-chain carboxylic acids. Under batch extraction conditions, the electrodialysis scheme enabled the recovery of $60 \%\left(\mathrm{~mol} \mathrm{~mol}^{-1}\right)$ of the total carboxylic acids present in the model fermentation broth. The particular arrangement of conventional monopolar ion exchange membranes and hydraulic recirculation loops allowed the progressive acidification of the extraction solution, enabling phase separation of caproic acid as an immiscible oil with $76 \%$ purity.

\section{INTRODUCTION}

The use of waste streams (e.g., from industry and agriculture) as a feedstock for the production of valuable chemical products is increasingly being recognized as a promising approach in the emerging circular economy. ${ }^{1}$ Among the technologies that are able to transform waste into chemicals, of particular interest is the conversion of gaseous wastes containing carbon dioxide $\left(\mathrm{CO}_{2}\right)$ using microbial electrosynthesis, that is, electricitydriven gas fermentation using acetogens. ${ }^{2}$ Typical products of electrosynthesis include short-chain carboxylic acids (SCCAs, i.e., linear saturated acids with two to four carbon atoms) and their corresponding alcohols. ${ }^{3,4}$ SCCAs are important platform chemicals that can serve as precursors in the production of plastics, fuels, and other chemicals that would otherwise be manufactured from nonrenewable sources. ${ }^{5}$ For example, acetic acid ( $\mathrm{C} 2)$ is used in the production of vinyl acetate and acetic anhydride, both important in the fabrication of polymers (e.g., polyvinyl acetate used in adhesives), ${ }^{6}$ whereas butyric acid (C4) is used in the production of polymers, flavour enhancers, perfumes, and prodrugs in pharmaceuticals, ${ }^{7}$ or it can be further converted into butanol and used as a dropin fuel. ${ }^{8,9}$

Despite the broad applications of SCCAs, their production through microbial electrosynthesis is constrained by their relatively low market price ${ }^{10}$ and by the fact that bio-based productions typically generate dilute aqueous mixtures of products, requiring expensive downstream processing for separation and purification. ${ }^{11,12}$ A possible approach to improve the product value, while at the same time reducing downstream processing requirements, is to combine microbial electrosynthesis with carbon chain-elongation to upgrade

Received: January 22, 2021

Accepted: February 25, 2021

Published: March 12, 2021 


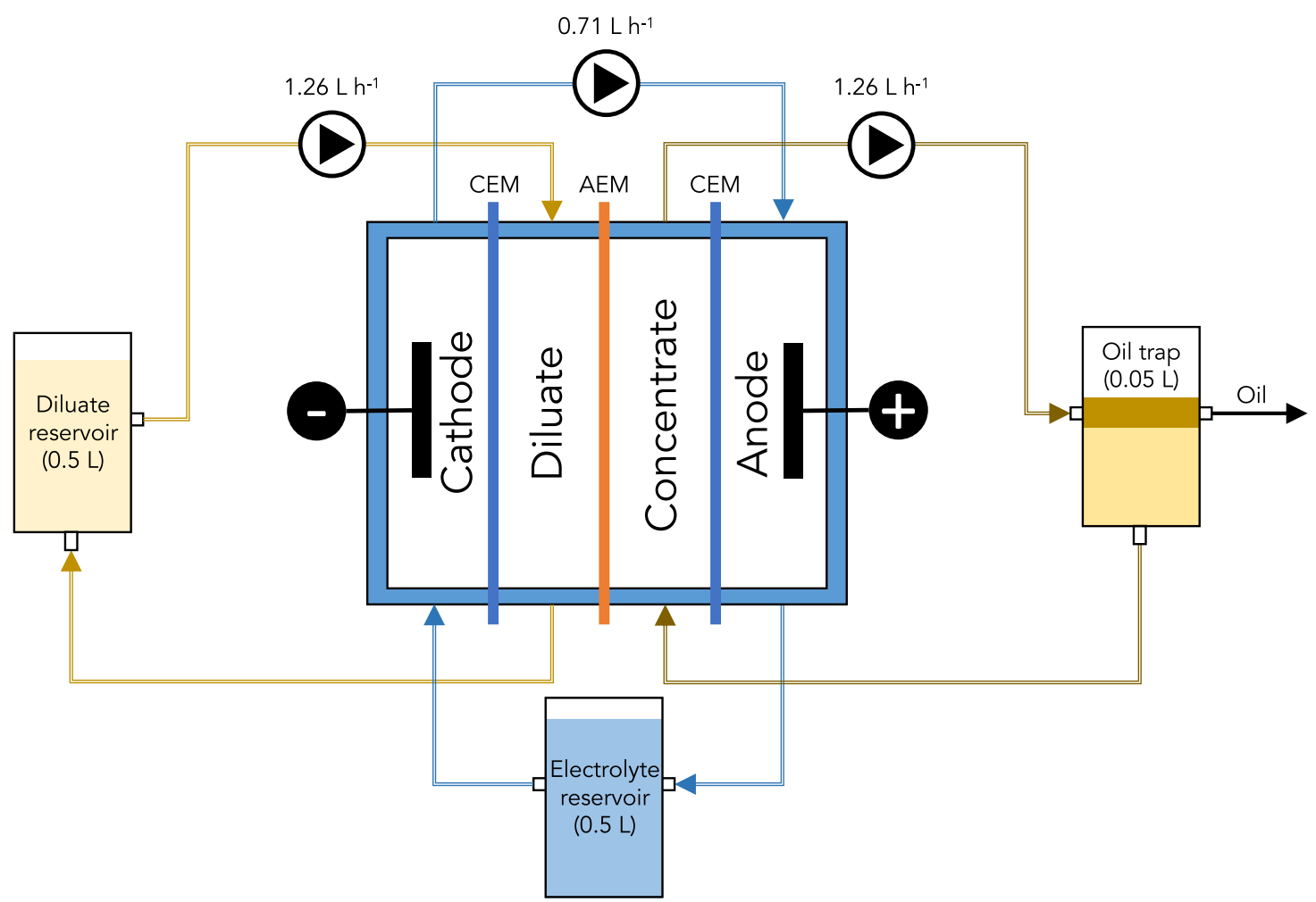

Figure 1. Schematic representation of the ED cell system and relevant fluxes. Cell's compartments were obtained by sandwitching together two CEMs and one AEM to yield a feed chamber (containing the diluate solution), an extraction chamber (containing the concentrate solution), and the two electrode chambers, cathode and anode, hosting the respective electrodes. The diluate solution was recycled through its reservoir, whereas the concentrate solution was pumped through an oil trap to allow phase separation and accumulation of caproic acid at the top of the trap, while the aqueous concentrate solution was recycled to the concentrate chamber in the ED unit. Anode and cathode solutions were recycled through the same reservoir.

SCCAs to medium-chain carboxylic acids (MCCAs), which comprise of six to 12 carbon atoms. ${ }^{11,13,14}$ Compared to SCCAs, MCCAs have a higher market price ${ }^{10,15}$ and a broad range of applications, for example, in the manufacture of pharmaceuticals, fragrances, rubbers, food additives, antimicrobial agents, lubricants, dyes, and renewable fuels. ${ }^{16,17}$ Further, compared to SCCAs, the higher hydrophobic character of MCCAs enables more easy separation from aqueous solutions. ${ }^{11}$

Production of MCCAs in electrochemical systems has been reported by many research groups. ${ }^{18-23}$ While this is promising, reported volumetric productivities and titers have thus far been well below those required for commercial viability. ${ }^{24}$ One of the reasons for constrained productivities is associated to the accumulation of fermentation products in the fermentation broth, which could lead to losses of activity due to thermodynamically constrained conversions or direct inhibition. ${ }^{25}$ This is particularly critical for MCCAs such as caproic (C6) and caprylic (C8) acids, for which inhibitory levels as low as 7.5 and $0.6 \mathrm{mM}$ have been observed. ${ }^{11,12} \mathrm{An}$ effective strategy to overcome inhibition and thereby increase production rates and selectivity toward target products is the continuous removal of fermentation products through in situ product recovery. ${ }^{25}$

Several methods can be applied to separate carboxylic acids from fermentation broths, including ion-exchange resins, ${ }^{26,27}$ liquid-liquid extraction, ${ }^{28}$ membrane-based extraction, ${ }^{29,30}$ and membrane electrodialysis (ED).$^{31-33}$ ED uses an electrical gradient between two electrodes (a cathode and an anode) to promote the migration of cations and anions in opposite directions from a feed solution (diluate) through a stack of ionexchange membranes, into an extraction solution (concentrate) where products are upconcentrated. Compared to other recovery methods, ED is attractive because (i) it can be powered with renewable electricity, (ii) it does not use hazardous chemicals for the recovery of the extracting material, (iii) it has high technological compatibility, and (iv) it is effective under $\mathrm{pH}$ conditions suitable to fermentation systems. $^{34}$ In conventional ED (CED), the repeating unit consists of three compartments: diluate, concentrate, and electrode compartments (anode and cathode), separated by monopolar anion and cation exchange membranes arranged between the electrodes. ${ }^{35-37}$ Such arrangements have been used to extract acetic, ${ }^{38}$ butyric, $^{39}$ lactic acids, ${ }^{40}$ as well as mixtures of volatile fatty acids (VFA). ${ }^{31}$ To improve the separation performance and to overcome some of the disadvantages of CED when applied to carboxylic acids extraction, including the requirement for extra supply of acids or bases to control the fermentation $\mathrm{pH}$, the use of bipolar membranes has been proposed. ${ }^{36}$ Compared to CED, $\mathrm{ED}$ with a bipolar membrane (i.e., EDBM) enables water dissociation into $\mathrm{H}^{+}$and $\mathrm{OH}^{-}$ions under the application of a reverse potential bias, thereby reducing or even eliminating the need for external supply of chemicals for $\mathrm{pH}$ regulation. ${ }^{36}$ EDBM has been applied successfully to the recovery of acetic acid, $^{41}$ lactic acid, ${ }^{42}$ and mixtures of VFAs. ${ }^{43}$ However effective, bipolar membranes have a number of disadvantages including high manufacturing costs, low stability, and short lifetime due to delamination of the layers. ${ }^{44} \mathrm{~A}$ variation of the EDBM that still allows water splitting is electro-ED (EED). 

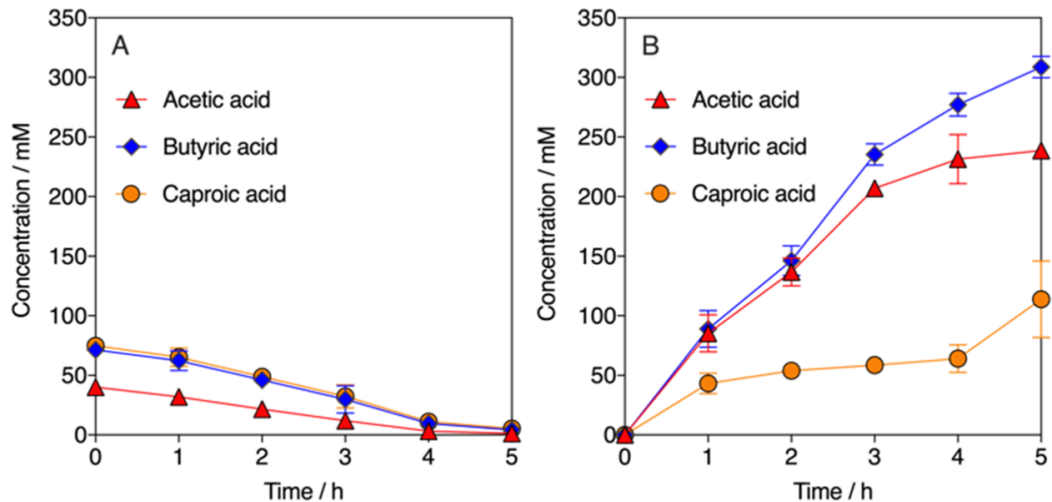

Figure 2. Concentration of carboxylic acids in aqueous solutions measured in (A) the diluate solution and (B) in the concentrate solution during batch extraction tests.

EED uses the anode and cathode reactions to provide $\mathrm{H}^{+}$and $\mathrm{OH}^{-}$through water electrolysis. As such, it can be implemented using conventional monopolar ion exchange membranes. This method and variations thereof have been proposed to recover formic, ${ }^{45}$ malic, ${ }^{46}$ lactic, $^{47}$ and acetic acids, ${ }^{48}$ as well as diluted mixtures of $\mathrm{C} 1-\mathrm{C} 6$ carboxylic acids. $^{34}$

Achieving proper $\mathrm{pH}$ stability during microbial electrosynthesis is crucial, especially when targeting longer-chain products. In fact, while carbon chain elongation is favored at around neutral $\mathrm{pH}$, mildly acidic conditions favor solventogenesis, though at the expenses of chain elongation. ${ }^{49,50}$ Under such conditions, the majority of the organic acids occur in the charged, unprotonated form, which makes ED particularly appropriate for product extraction. Accordingly, in this study, we tested a simple ED system based on the EED scheme, comprising of two lateral cation exchange membranes (CEMs) and a central anion exchange membrane (AEM) to yield a diluate and a concentrate compartments, while an acidic electrolyte solution was recycled through both anode and cathode compartments. This ED scheme was applied to treat a model solution containing an heterogeneous mixture of acetic, butyric, and caproic acids, mimicking an electrosynthesis fermentation effluent. ${ }^{18-20}$ This particular arrangement allowed the recycling of $\mathrm{H}^{+}$derived from the dissociation of carboxylic acids in the diluate solution and those produced through electrolytic water splitting, thereby enabling the progressive acidification of the concentrate solution and the spontaneous phase separation of caproic acid as an immiscible oil.

\section{RESULTS AND DISCUSSION}

2.1. Carboxylic Acid Extraction from the Model Microbial Electrosynthesis Effluent. A schematic representation of the laboratory scale ED system used in this study is provided in Figure 1, while detailed information is provided in Section 4.1 of Methods. Electromigration of carboxylic acids from the diluate to the concentrate solutions was tested during the course of batch extraction tests under a fixed applied current of $0.8 \mathrm{~A}$. This current was selected on the basis of the highest caproic acid recovery obtained through a series of preliminary experiments (data not shown).

Figure 2 reports the concentration versus time profiles of carboxylates (i.e., including both dissociated and undissociated forms of carboxylic acids) in the diluate and in the concentrate solutions during the $5 \mathrm{~h}$ batch extraction experiments. In the diluate solution, the concentration of acetic, butyric, and caproic acids decreased from $40 \pm 1,71 \pm 1$, and $75 \pm 1 \mathrm{mM}$, respectively, to $1 \pm 1,4 \pm 3$, and $5 \pm 4 \mathrm{mM}$ (Figure $2 \mathrm{~A}$ ). Conversely, their concentration in the concentrate solution increased respectively to values up to $238 \pm 3,309 \pm 9$, and $114 \pm 32 \mathrm{mM}$, indicating the upconcentration of carboxylic acids (Figure 2B).

The average total flux of carboxylic acids toward the concentrate chamber was equal to $1.30 \pm 0.08 \mathrm{~mol} \mathrm{~m}^{-2} \mathrm{~h}^{-1}$ (equivalent to $113 \pm 7 \mathrm{~g} \mathrm{~m}^{-2} \mathrm{~h}^{-1}$ ), with individual fluxes measured for acetic, butyric, and caproic acids equal to, respectively, $0.40 \pm 0.03 \mathrm{~mol} \mathrm{~m}^{-2} \mathrm{~h}^{-1}\left(23 \pm 2 \mathrm{~g} \mathrm{~m}^{-2} \mathrm{~h}^{-1}\right), 0.56$ $\pm 0.03 \mathrm{~mol} \mathrm{~m}^{-2} \mathrm{~h}^{-1}\left(49 \pm 3 \mathrm{~g} \mathrm{~m}^{-2} \mathrm{~h}^{-1}\right)$, and $0.34 \pm 0.02 \mathrm{~mol}$ $\mathrm{m}^{-2} \mathrm{~h}^{-1}\left(39 \pm 2 \mathrm{~g} \mathrm{~m}^{-2} \mathrm{~h}^{-1}\right)$ (Table 1). A significant flux of water $\left(0.5 \pm 0.2 \mathrm{~L} \mathrm{~m}^{-2} \mathrm{~h}^{-1}\right)$ to the concentrate chamber was also observed, resulting in an additional $21 \pm 7 \mathrm{~mL}$ of water at the end of the batch extraction test.

Measurements of variation of liquid volumes in the three solutions suggest that the majority of water flux originated from the diluate compartment while only a small fraction derived from the anode and cathode electrolyte (data not shown). Due to the relatively small current densities applied in this study $\left(<1 \mathrm{~A} \mathrm{dm}^{-2}\right)$, most of the water transport observed should be linked to hydraulic osmosis resulting from the concentration gradient between diluate and concentrate solutions, rather than to electro-osmosis, ${ }^{51,52}$ while additional leakages due to differential pressures between compartments should also be considered negligible due to the low recycle rates applied.

2.2. Production of Acidity in the Concentrate Chamber and Phase Separation of Caproic Acid. Figure 3 shows measurements of conductivity and $\mathrm{pH}$ in the ED system' solutions during the batch extraction test. In the diluate compartment, the conductivity decreased at a rate of $2.5 \mathrm{mS} \mathrm{cm}{ }^{-1}$ per hour from an initial value of $13.20 \pm 0.02 \mathrm{mS}$ $\mathrm{cm}^{-1}$ to a final value of $0.85 \pm 0.05 \mathrm{mS} \mathrm{cm} \mathrm{cm}^{-1}$ (Figure 3A). Concurrently, smaller $\mathrm{pH}$ variations were observed in the diluate, where it remained stable at a value of around 6 for most of the extraction tests (except for the drop observed at 5 $\mathrm{h})$. The reduction of conductivity observed in the diluate is to be linked to the migration of dissociated carboxylates to the concentrate compartment (Figure 3 and Table 1). However, the values of current efficiency observed suggests that only 37.7 $\pm 2.4 \%$ of the charge could be associated to carboxylic acids migration (Table 1). This relatively low current efficiency can be understood by considering the high voltage required to 
Table 1. ED Process Evaluation through Batch Extraction Tests

\begin{tabular}{lr}
\multicolumn{2}{c}{ Current Efficiency, $\eta(\%)$} \\
acetate & $11.5 \pm 1.0$ \\
butyrate & $16.3 \pm 0.8$ \\
caproate & $9.8 \pm 0.6$ \\
total $(\mathrm{C} 2+\mathrm{C} 4+\mathrm{C} 6)$ & $37.7 \pm 2.4$ \\
$\mathrm{H}^{+}$ & $0.6 \pm 0.2$ \\
total & $38 \pm 2$
\end{tabular}

Flux of Carboxylic Acids to the Concentrate Chamber, $J_{\text {C.A. }}\left(\mathrm{mol} \mathrm{m}^{2} \mathrm{~h}^{-1}\right)$
$\begin{array}{ll}\text { acetate } & 0.40 \pm 0.03 \\ \text { butyrate } & 0.56 \pm 0.03 \\ \text { caproate } & 0.34 \pm 0.02 \\ \text { total }(\mathrm{C} 2+\mathrm{C} 4+\mathrm{C} 6) & 1.30 \pm 0.08\end{array}$

Flux of Protons to the Concentrate Chamber, $J_{\mathrm{H}^{+}}\left(\mathrm{mol} \mathrm{m} \mathrm{m}^{2}\right)$ $0.02 \pm 0.01$

Flux of Water to the Concentrate Chamber, $J_{\mathrm{H}_{2} \mathrm{O}}\left(\mathrm{L} \mathrm{m}^{2} \mathrm{~h}^{-1}\right)$ $0.5 \pm 0.2$

Carboxylic Acids Recovery in the Concentrate Chamber, $R_{\mathrm{e}}$ (Aqueous Phase) $\left(\mathrm{mol} \mathrm{mol}{ }^{-1} \%\right)$

\begin{tabular}{lc} 
acetate & $84 \pm 6$ \\
butyrate & $61 \pm 4$ \\
caproate & $22 \pm 7$ \\
total $(\mathrm{C} 2+\mathrm{C} 4+\mathrm{C} 6)$ & $50 \pm 6$ \\
\multicolumn{2}{c}{} \\
Carboxylic Acids Recovery in the Concentrate $\mathrm{Chamber,}_{\mathrm{e}}$ \\
$\quad$ (Aqueous Phase + Oily Phase) $\left(\mathrm{mol} \mathrm{mol}^{-1} \%\right)$ \\
acetate & $86 \pm 6$ \\
butyrate & $68 \pm 3$ \\
caproate & $39 \pm 2$ \\
total (C2 + C4 + C6) & $60 \pm 3$ \\
$\quad$ Specific Energy Consumption, $E_{\mathrm{CA}}\left(\mathrm{kW} \mathrm{h} \mathrm{kg}^{-1}\right)$ \\
total (C2 + C4 + C6) & $5.0 \pm 0.2$
\end{tabular}

maintain a fixed current of $0.8 \mathrm{~A}$ (Figure 3D), which resulted in significant water electrolysis. In addition, it is reasonable to assume that other ionic species present in the solutions competed with the carboxylates to maintain charge neutrality. Phosphate anions $\left(\mathrm{PO}_{4}{ }^{3-}\right)$, together with sodium $\left(\mathrm{Na}^{+}\right)$and potassium $\left(\mathrm{K}^{+}\right)$cations, were provided together with the buffer solution in the diluate chamber; it is therefore possible that these species migrated toward the cathode compartment through the CEM $\left(\mathrm{Na}^{+}\right.$and $\left.\mathrm{K}^{+}\right)$and toward the concentrate chamber through the AEM $\left(\mathrm{PO}_{4}{ }^{3-}\right)$. Measurements of ionic species in the three reservoirs at the beginning and at the end of the batch extraction tests confirm this scenario (Table S1). While the migration of protons and hydroxyls from the diluate compartment (respectively to the cathode and to the concentrate chambers) was possible, the stability of the $\mathrm{pH}$ measured in the diluate chamber throughout the majority of the test (Figure 3A) suggests that it had minor relevance compared to the migration of other species.

In the concentrate solution, the conductivity increased sharply during the first hour from a background level of $0.47 \pm$ $0.03 \mathrm{mS} \mathrm{cm}^{-1}$ to a value of $13.8 \pm 5.6 \mathrm{mS} \mathrm{cm}^{-1}$, after which it stabilized at around ca. $15 \mathrm{mS} \mathrm{cm} \mathrm{cm}^{-1}$ for the remaining of the extraction test (Figure 3B). Concurrently, the $\mathrm{pH}$ in this compartment dropped sharply from $7.4 \pm 0.1$ to $2.0 \pm 0.2$ in the first hour and then it remained stable at around a value of ca. 1.9 until the end of the test (Figure 3B). The increase in conductivity in the concentrate can be attributed to the transport of phosphate ions from the diluate chamber and of sodium and potassium ions from the anode chamber. This is corroborated by the reduction of conductivity observed in the anode/cathode electrolyte as well as by measurement of ionic species in the three solutions (Table S1).

The low $\mathrm{pH}$ of the anode and cathode reservoir (Figure 3C) guaranteed a significant proton flux from the anode reservoir to the concentrate chamber (at a rate of $0.02 \pm 0.01 \mathrm{~mol} \mathrm{~m}^{-2} \mathrm{~h}^{-1}$, Table 1). While this flux can only account to less than $1 \%$ of the charge balance, it was nevertheless responsible for the $\mathrm{pH}$ drop observed in the concentrate solution and contributed to the increase in its conductivity (Figure 3B). Conversely, while the concentration of carboxylates also increased in the concentrate (Figure $2 \mathrm{~B}$ ), their contribution to the conductivity is expected to be negligible at the low $\mathrm{pH}$ observed, since the majority of the carboxylates would be in the undissociated form (see discussion below).

To assure a constant current of $0.8 \mathrm{~A}$ throughout the extraction test, the voltage across the ED system was manually increased over time. Figure $3 \mathrm{D}$ shows the voltage versus time profile, highlighting that the energy requirement increased as the experiment progressed, with a maximum voltage of $14.1 \pm$ $0.4 \mathrm{~V}$ required at time $5 \mathrm{~h}$. This high voltage demand is likely due to the reduction of the conductivity in the diluate chamber-where it reached values below $1 \mathrm{mS} \mathrm{cm}^{-1}$ toward the end of the experiment-which is expected to result in an increase of the ohmic resistance of the system. ${ }^{53}$ Membrane scaling was not observed during our experiments and similar voltage versus time profiles were observed after each extraction test, suggesting that membrane integrity was maintained across our experimentation.

Due to the different liquid volume of the diluate and concentrate reservoirs (respectively 0.5 and $0.050 \mathrm{~L}$ ), carboxylic acid migration through the ED unit resulted in average upconcentration factors in the aqueous solution of the concentrate chamber of $5.9 \pm 0.2,4.3 \pm 0.2$, and $1.5 \pm 0.4$, respectively, for acetic, butyric, and caproic acids (Figure 2), resulting in recovery efficiencies $R_{\mathrm{e}}$ for the carboxylic acids contained in the aqueous solution of the concentrate chamber of $84 \pm 6 \%\left(\mathrm{~mol} \mathrm{~mol}^{-1}\right), 61 \pm 4 \%$, for acetic and butyric acid, and only $22 \pm 7 \%$ for caproic acid, in spite of the comparable fluxes observed for all three carboxylates tested (Table 1). This apparent mismatch between the high fluxes and low recovery efficiency observed for caproic acid can be understood by considering that a considerable fraction of caproate formed an oily phase separated from the aqueous solution in the concentrate chamber. In fact, while SCCAs such as acetic and butyric acids are miscible in aqueous solutions, the hydrophobic carbon chains of MCCAs such as caproic acid make them poorly soluble in water when in their undissociated acid form. We used this property to naturally separate caproic from the aqueous solution in the extraction solution. The progressive acidification of the concentrate solution resulting from proton migration from the anode compartment led to a drop of the $\mathrm{pH}$ in this chamber to a value of $c a .1 .9$ within the first hour of batch extraction (Figure 3B). At this low $\mathrm{pH}$, $>99 \%$ of the measured caproic acid (i.e., $>13.1 \mathrm{~g} \mathrm{~L}^{-1}$ ) can be determined to be in the protonated form (the $\mathrm{p} K_{\mathrm{a}}$ value of caproic acid is equal to 4.88). ${ }^{11}$ This is higher than the maximum solubility of undissociated caproic acid (equal to 

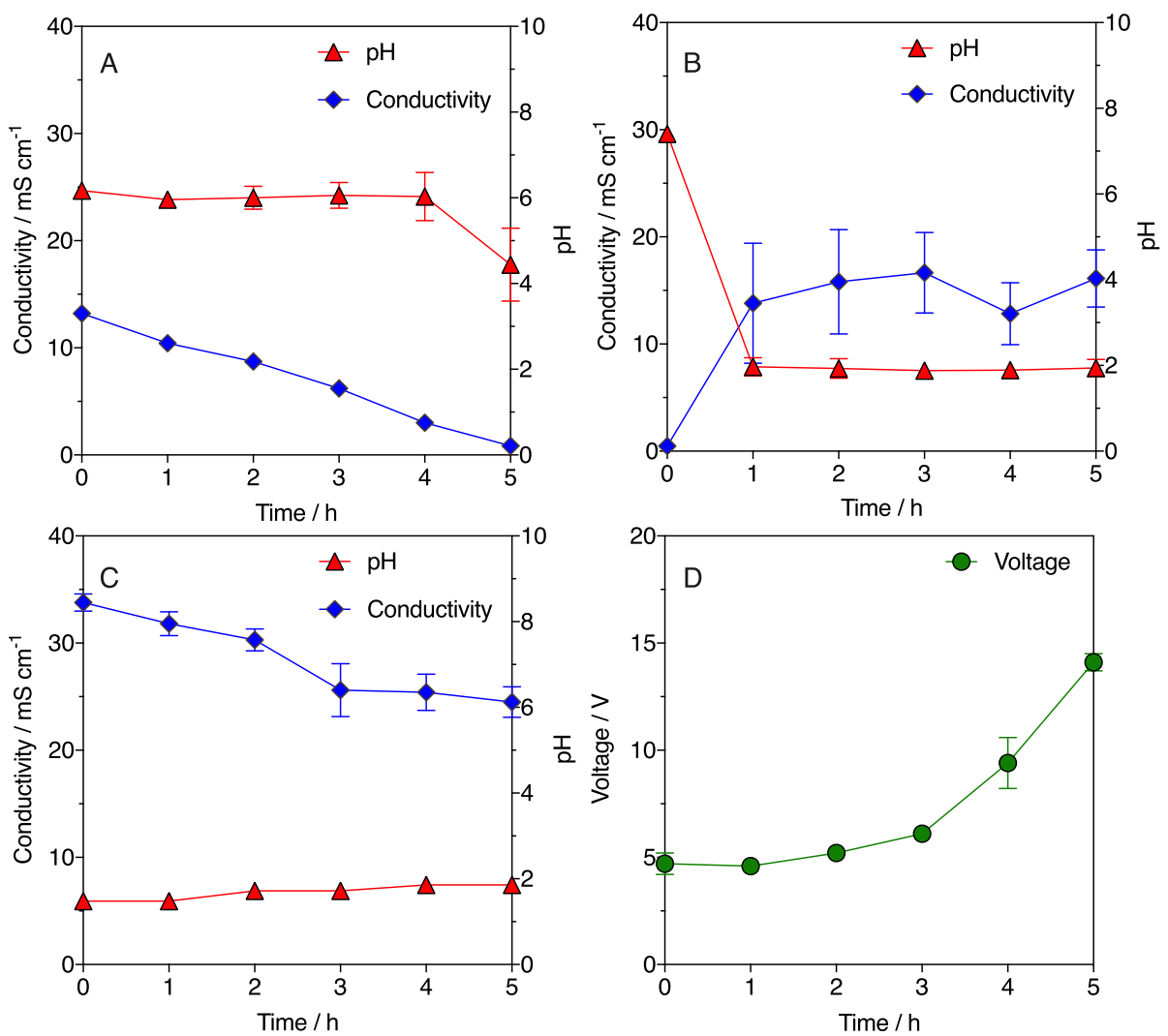

Figure 3. Measurements of conductivity and $\mathrm{pH}$ in (A) the diluate solution, (B) in the concentrate solution, and (C) in the combined anode and cathode solutions during batch extraction tests. (D) Measurements of the applied voltage required to deliver a constant current of 0.8 A.

$\left.10.82 \mathrm{~g} \mathrm{~L}^{-1}\right){ }^{11}$ This resulted in the spontaneous separation of caproate as a distinctive oily phase, forming at a rate of $49 \pm 10$ $\mathrm{mL} \mathrm{m} \mathrm{m}^{-2} \mathrm{~h}^{-1}$, in the concentrate solution, and accumulating in the oil trap (Figure 1), where it reached a maximum volume of $1.5 \pm 0.4 \mathrm{~mL}$ at the end of the extraction test. Analysis of its composition revealed that this oily phase comprised of $76 \pm$ $1 \%\left(\mathrm{~g} \mathrm{~g}^{-1}\right)$ caproic acid, $23 \pm 1 \%$ butyric acid, and only $2 \pm$ $1 \%$ acetic acid (Figure 4). Importantly, taking into account also the oily phase, the total carboxylic acids recovery efficiency $R_{\mathrm{e}}$ reported in Table 1 increased from $50 \pm 6$ to $60 \pm 3 \%$, with the increase due to the higher fraction of caproic and butyric acid now included in the calculations (in fact, the $R_{\mathrm{e}}$ for caproic and butyric acids increased from $22 \pm 7$ to $39 \pm 2 \%$ and from $61 \pm 4$ to $68 \pm 3 \%$, while it only increased from $84 \pm$

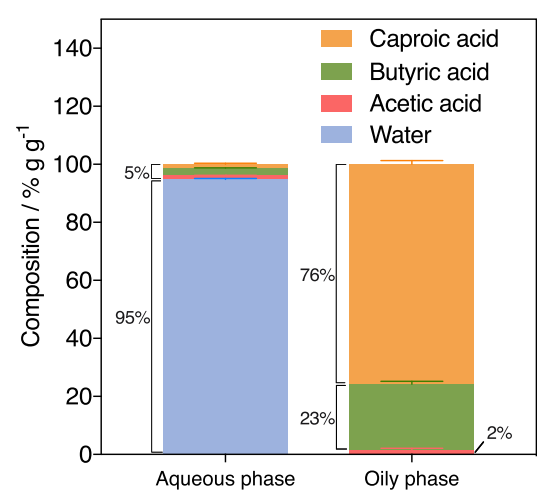

Figure 4. Breakdown of carboxylic acids in the concentrate compartment (aqueous solution and oily phase) at the end of the batch extraction tests.
6 to $86 \pm 6 \%$ for acetic acid, Table 1). This is not surprising considering that the large majority of the oily phase comprised of caproic acid (Figure 4). Although these recovery efficiencies were significantly lower than values reported for SCCAs by Zhang and Angelidaki using $\mathrm{EDBM}^{54}$ or Jones et al., ${ }^{31}$ using $\mathrm{CED}$, they are in line with those reported by $\mathrm{Xu}$ et al., ${ }^{16}$ for an integrated system comprising of pertraction and membrane electrolysis.

It is important to note that at the end of the batch extraction tests, it was not possible to account for all carboxylates introduced in the diluate solution. Figure 5 displays the breakdown of carboxylic acids at the end of the tests, including the fraction still available in the diluate chamber and the fractions extracted in the concentrate chamber, measured in both the aqueous and oily phases. The data show that a significant $38 \pm 2 \%\left(\mathrm{~g} \mathrm{~g}^{-1}\right)$ of the total carboxylates was unaccounted for at the end of the batch extraction. Importantly, the fraction of unaccounted caproic acid relatively to the total introduced is significantly higher compared to that observed for other carboxylates (55 $\pm 3 \%$ vs $26 \pm 2 \%$ measured for butyric and $12 \pm 5 \%$ for acetic acids, Figure 5). This can be explained by noting that a significant build-up of the oily phase was observed in the concentrate compartment (including membranes) and its hydraulic recirculation loop (including tubing and glassware), which made it impossible to accurately measure its total volume at the end of the batch extraction. Even taking into account the losses of carboxylic acids in the ED system, the specific energy demand $\left(E_{\mathrm{CA}}\right)$ was determined to be as low as $5.0 \pm 0.2 \mathrm{~kW} \mathrm{~h} \mathrm{~kg}^{-1}$ of total carboxylic acids extracted in the concentrate chamber (including carboxylates found in the aqueous and oily phases). Interestingly, if we only consider the fraction of caproate 


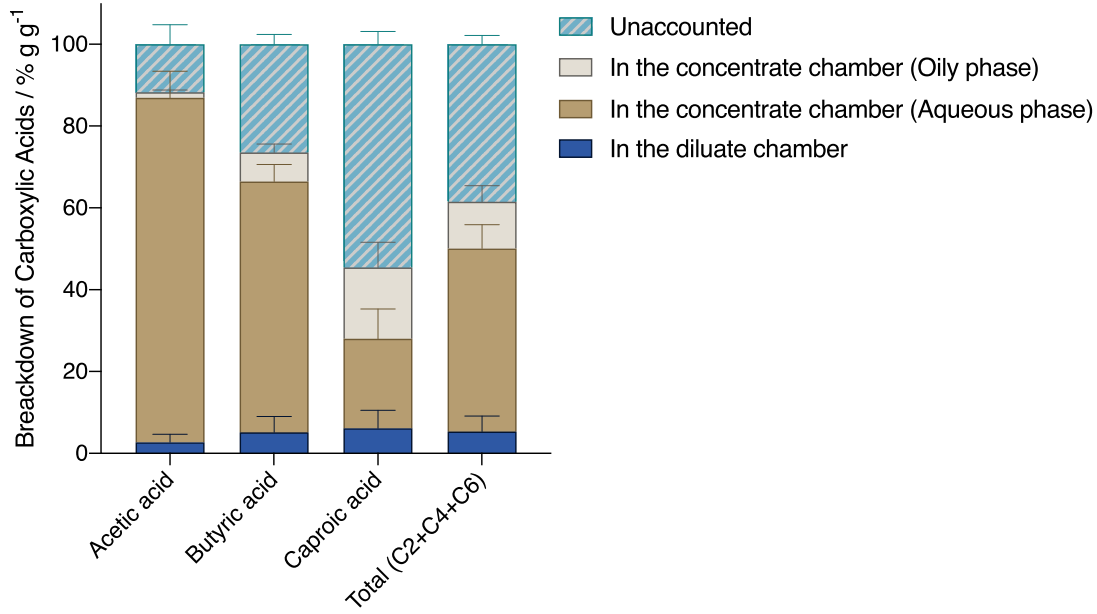

Figure 5. Breakdown of carboxylic acids measured in the concentrate solution at the end of the batch extraction tests, expressed as a percentage (g $\mathrm{g}^{-1}$ ) of their respective initial levels measured in the diluate compartment at the beginning of the batch extraction tests.

extracted in the concentrate, the specific energy requirement increases significantly to $c a .35 \mathrm{~kW} \mathrm{~h}$ per $\mathrm{kg}$ of caproic acid. However, this specific energy demand likely represents an overestimation of the actual energy required for caproate extraction. In fact, given the properties of caproic acid, specifically its $\mathrm{p} K_{\mathrm{a}}(=4.88),{ }^{11}$ and the $\mathrm{pH}$ of the concentrate solution $(<2)$, one could reasonably assume that the majority of the unaccounted caproate is distributed in the oily build-up observed in the concentrate, as discussed above. If, for the sake of the argument, we sum together the caproate measured in the oily phase and all of the unaccounted caproate in the concentrate compartment, the specific energy demand can be then estimated at $c a .8 \mathrm{~kW} \mathrm{~h} \mathrm{~kg}$, which is in line with reported energy requirements for electrodialytic carboxylic acid extraction. ${ }^{16,55}-57$

The high efficiency in the extraction of MCCAs, the chemical-free acidification, and the excess water flux to the concentrate chamber observed during electromigration make this proposed ED system particularly suitable for coupling with a microbial electrosynthesis bioreactor producing mediumchain carboxylates from carbon dioxide and electricity (e.g., by recycling the cathodic fermentation broth through the diluate compartment of the ED system). ${ }^{4,20}$ In fact, in order to promote the elongation of acetate to MCCAs, the cathode compartment of microbial electrosynthesis bioreactors is typically maintained under mildly acidic conditions to stimulate the reassimilation of acetate into its corresponding alcohol ethanol, ${ }^{49,50}$ which is then used as the electron donor in the production of longer-chain carboxylates through the reverse $\beta$-oxidation chain elongation pathway. ${ }^{58}$ Recently, we proposed the use of $\mathrm{CO}_{2}$ dosing to achieve both $\mathrm{pH}$ control in the cathode chamber of a microbial electrosynthesis reactor producing MCCAs, while also providing the carbon feedstock. ${ }^{20}$ However, the development of $\mathrm{pH}$ gradients between anode and cathode chambers resulting from the competing transport of ionic species other than protons and hydroxyls through the ion exchange membranes typically used in bioelectrochemical systems ${ }^{59}$ makes this option for $\mathrm{pH}$ control not ideal since it can easily result in excess carbon dioxide dosing, thereby yielding low carbon recovery efficiencies. Conversely, with a microbial electrosynthesis bioreactor integrated with an ED system for in-line caproate extraction as that demonstrated here, $\mathrm{pH}$ control in the cathode compartment could be achieved by recycling the excess acidic aqueous phase of the concentrate chamber (in this work, comprising for more than $80 \%$ of acetic and butyric acids) to the bioreactor. Besides the inherent benefits provided by the continuous in-line extraction of fermentation products, which include higher production rates and product selectivity, ${ }^{25}$ this solution would also allow additional advantages, including improved carbon recovery efficiency toward longer-chain carboxylates (since the more soluble SCCAs acetate and butyrate would be recycled back to the bioreactor for further chain elongation) and the recovery of the water transported to the concentrate solution as the result of electromigration. Clearly, technology integration would still require careful process design in order to match the requirement of the two units, at the same time targeting the improvement of MCCA recovery efficiency and the reduction of the electric power requirement (e.g., by employing different membrane materials and multiple ED stacks and by optimizing the composition of the electrolytes in the concentrate, anode, and cathode chambers). Effective strategies to manage microbial and particulate matter should also be considered to avoid losses of performance of the ED system due to membrane fouling. ${ }^{31}$ These might involve, for example, the use of filtration units ahead of ED, as suggested recently. ${ }^{60,61}$

\section{CONCLUSIONS}

In this work, we investigated the use of membrane ED to extract and separate MCCAs from a synthetic fermentation broth. Carboxylates were extracted at a total recovery efficiency of $60 \pm 3 \%\left(\mathrm{~mol} \mathrm{~mol}^{-1}\right)$ with an energy investment of $\mathrm{ca} .5 \mathrm{~kW}$ $\mathrm{h}$ per $\mathrm{kg}$ carboxylic acid extracted. A simple arrangement consisting of conventional anion and cation exchange membranes and recirculation loops allowed the supply of protons to the concentrate chamber at a rate of $0.02 \pm 0.01$ mol $\mathrm{H}^{+}$per square meter of membrane per hour, resulting in the progressive drop in the $\mathrm{pH}$ to a value of $c a .1 .9$ without requiring the use of more expensive bipolar membranes in the ED stack. ${ }^{43,44}$ This allowed the spontaneous formation and separation of an oily phase comprising of $76 \pm 1 \%\left(\mathrm{~g} \mathrm{~g}^{-1}\right)$ of caproic acid, $23 \pm 1 \%$ of butyric acid, and $2 \pm 1 \%$ of acetic acid. This ED separation scheme is expected to be particularly suitable for in-line extraction of medium-chain carboxylates produced through microbial electrosynthesis, since the excess 
acidic aqueous solution containing acetic and butyric acids could be recycled back to the cathode compartment for further elongation and chemical-free $\mathrm{pH}$ control of the fermentation broth.

\section{METHODS}

4.1. ED System and Operations. The ED system (Figure 1) was assembled using two CEMs and one AEM (RALEX, MEGA, Czech Republic). Each membrane had an effective membrane area of $86.6 \mathrm{~cm}^{2}$. Woven polyester fabric spacers with integrated silicon gaskets (thickness $0.45 \mathrm{~mm}$, Shandong Tianwei Membrane Technology Co. Ltd., China) were interposed between the ion-exchange membranes to yield four compartments, namely cathode, diluate, concentrate, and anode chambers, each with an internal working volume of 3.9 $\mathrm{cm}^{3}$. The ED system was held together between two Perspex frames using stainless steel rods and nuts. Anode and cathode chambers were equipped with titanium plates coated with ruthenium serving as electrodes (projected area: $62.2 \mathrm{~cm}^{2}$, Shandong Tianwei Membrane Technology Co. Ltd., China). To ensure external electric connection, two rods were welded to the plates. Diluate and the concentrate solutions were recycled at a rate of $1.26 \mathrm{~L} \mathrm{~h}^{-1}$ using a multichannel peristaltic pump (323S Watson-Marlow Pty Limited NSW, Australia). The diluate recirculation loop included a $500 \mathrm{~mL}$ bottle as a reservoir. The concentrate recirculation loop included a $50 \mathrm{~mL}$ oil trap to allow the separation and accumulation of caproic acid outside of the concentrate compartment (Figure 1). Anode and cathode chambers were recycled through the same $500 \mathrm{~mL}$ reservoir at a rate of $0.71 \mathrm{~L} \mathrm{~h}^{-1}$ using a single-channel peristaltic pump (Aqua PER-R, Italy).

4.2. Synthetic Mediums. The diluate solution was designed to mimic the fermentation broth of microbial electrochemical systems producing short- and medium-chain carboxylates from $\mathrm{CO}_{2}$ through microbial electrosynthesis. ${ }^{20}$ It comprised of $0.5 \mathrm{~L}$ of reverse osmosis (RO) water containing per liter: $6 \mathrm{~g}$ of $\mathrm{Na}_{2} \mathrm{HPO}_{4}, 3 \mathrm{~g} \mathrm{KH}_{2} \mathrm{PO}_{4}, 8.25 \mathrm{~g}$ of $n$-caproic acid [equivalent to $71 \mathrm{mmol}$ ], $5.99 \mathrm{~g}$ of $n$-butyric acid [68 $\mathrm{mmol}$, and $3.28 \mathrm{~g}$ of acetic acid [ $40 \mathrm{mmol}$ ]. To enable carbon chain elongation, the $\mathrm{pH}$ of electro-fermentations broths is typically maintained under mildly acidic conditions to promote acetate reassimilation into ethanol (solventogenesis). ${ }^{4,20}$ As such, prior to the batch extraction tests, the $\mathrm{pH}$ of the solution was adjusted to a value between 6.0 and 6.2 through additions of $\mathrm{NaOH}$. The concentrate solution comprised of $50 \mathrm{~mL}$ of tap water. The shared anode and cathode electrolyte consisted of $0.5 \mathrm{~L}$ of $\mathrm{RO}$ water containing, per liter: $3 \mathrm{~g}$ of $\mathrm{Na}_{2} \mathrm{SO}_{4}$ and 40 $\mathrm{mL}$ of $5 \mathrm{M}$ solution of $\mathrm{H}_{2} \mathrm{SO}_{4}$. The use of sulfuric acid guaranteed high availability of protons to enable the progressive acidification of the concentrate solution along with the minimization of overpotentials associated to water electrolysis.

4.3. Batch Extraction Tests. The ED system was operated under galvanostatic mode by applying a fixed current of $0.8 \mathrm{~A}$ using a DC power supply (ISO-TECH IPS 2303, Philippines). The functioning principle is outlined in Figure 6. The establishment of the electric field across the electrodes enables the transport of ionic species across the ion-exchange membranes comprising the ED stack. From the diluate chamber, anions (i.e., dissociated carboxylic acids, phosphate ions, and hydroxyls) migrate toward the anode chamber. Because of the AEM and CEMs arrangement, these anions are however retained in the concentrate. Similarly, cations in the

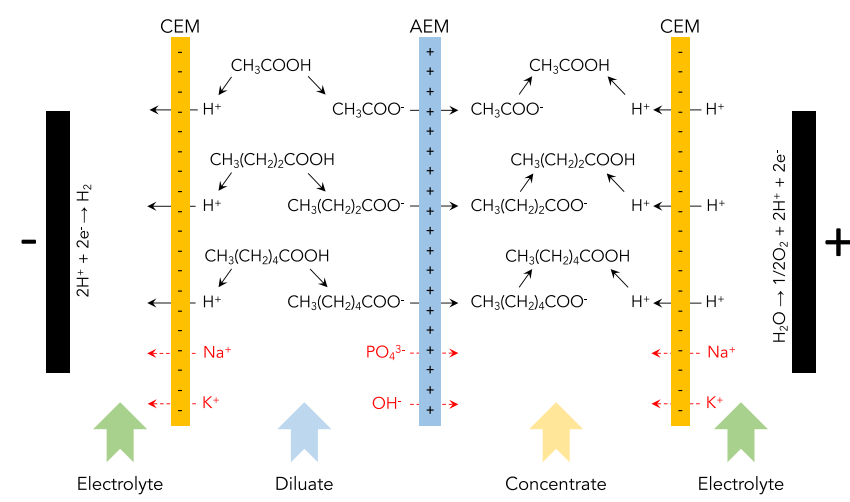

Figure 6. Schematic representation of the ED stack used to recover carboxylic acids. Black solid arrows indicated desired fluxes; red dashed arrows indicate competing fluxes.

anode chamber (protons and sodium ions present in the anode and cathode electrolyte, and additional protons derived from water electrolysis at the anode) migrate toward the cathode through the CEM separating the anode and the concentrate chambers. Because of the presence of the AEM between diluate and concentrate chambers, these cations are retained in the concentrate chamber, where the dissociated carboxylic acids recombine with the protons.

Additional sodium and potassium cations can also enter the cathode chamber (and thereby the concentrate chamber) from the diluate compartment through the CEM at the side of the cathode chamber (Figure 6). Conversely, because of the presence of two CEMs separating anode and cathode compartments from the concentrate and diluate chambers, respectively, negatively charged sulfates present in the anode and cathode electrolyte and hydroxyls generated through water electrolysis at the cathode are retained within the anode/ cathode shared electrolyte.

During the extraction tests, $2 \mathrm{~mL}$ of liquid samples were taken hourly from each reservoir and immediately used for measurement of $\mathrm{pH}$ and conductivity using portable measuring units (LAQUAtwin B-712 and B-771 respectively, HORIBA, Japan). Samples were also taken and analyzed for the liquidphase components (see Section 4.4 below). The duration of the batch extraction experiment was dictated by the conductivity of the diluate solution, the reduction of which to values below $1 \mathrm{mS} \mathrm{cm} \mathrm{cm}^{-1}$ was considered as indicative of the successful migration of ionic species, including carboxylic acids. The typical duration of the extraction tests was $5 \mathrm{~h}$.

4.4. Chemical Analyses. Liquid-phase samples taken from the ED system were immediately filtered through a $0.22 \mu \mathrm{m}$ pore filter and analyzed for carboxylic acids content via gas chromatography (GC) (Agilent Technologies 7890A GC System, USA), equipped with a polar capillary column (DBFFAP $30 \mathrm{~m} \times 0.53 \mathrm{~mm} \times 1.0 \mu \mathrm{m}$ ) and flame ionization detector (make-up flow: $10 \mathrm{~mL} \mathrm{~min}{ }^{-1} \mathrm{~N}_{2}: 250{ }^{\circ} \mathrm{C}$ ). Potassium and sodium ions were measured by inductively coupled plasma optical emission spectrophotometry (ICP-OES) with an ion chromatograph (PerkinElmer ICP-OES Optima 7300DV). Phosphate ions were measured via flow injection analysis (Lachat QuickChem 8500 Flow Injection Analyzer, Lachat Instruments, USA).

4.5. Calculations. Material fluxes $J_{i}\left(\mathrm{~mol} \mathrm{~m}^{-2} \mathrm{~h}^{-1}\right)$ of species $i$ to the concentrate compartment through the AEM membrane were determined as 


$$
J_{i}=\frac{\left(C_{i}^{\mathrm{C}, \text { final }} \cdot V^{\mathrm{C}, \text { final }}-C_{i}^{\mathrm{C} \text {,initial }} \cdot V^{\mathrm{C} \text {,initial }}\right)}{A \cdot t}
$$

where $C_{i}^{\text {, initial }}$ and $C_{i}^{\mathrm{C}, \text { final }}$ are, respectively, the measured concentrations of specie $i$ in the concentrate solution at the beginning and at the end of the batch extraction experiment $\left(\mathrm{mol} \mathrm{L}{ }^{-1}\right), V^{\text {C,initial }}$ and $V^{\mathrm{C} \text {,final }}$ are respectively the liquid volume of the concentrate solution at the beginning and at the end of the batch extraction test $(\mathrm{L}), A$ is the surface area of the AEM $\left(\mathrm{m}^{2}\right)$, and $t$ is the duration of the batch extraction test (h).

The same formalism was used to determine the water flux (L $\left.\mathrm{m}^{-2} \mathrm{~h}^{-1}\right)$

$$
J_{\mathrm{H}_{2} \mathrm{O}}=\frac{\left(V^{\mathrm{C}, \text { final }}-V^{\mathrm{C}, \text { initial }}\right)}{A \cdot t}
$$

as well as the proton flux to the concentrate solution $\left(\mathrm{mol} \mathrm{m}^{-2}\right.$ $\left.\mathrm{h}^{-1}\right)$

$$
J_{\mathrm{H}^{+}}=\frac{\left(V^{\mathrm{C}, \text { final }} \cdot 10^{-\mathrm{pH}^{\mathrm{C}, \text { final }}}\right)-\left(V^{\mathrm{C}, \text { initial }} \cdot 10^{-\mathrm{pH}^{\mathrm{C}, \text { initial }}}\right)}{A \cdot t}
$$

The current efficiency $\eta$ (\%) was determined as the ratio between the electric charge associated to the transfer of charged species and the total charge transferred as electric current during the batch extraction test

$$
\eta_{i}=\frac{z_{i} \cdot J_{i} \cdot F \cdot A}{I} \times 100 \%
$$

where $z_{i}$ is the charge number of the species $i, J_{i}$ is the flux of species $i$ during the batch extraction (eq 1), $F$ is the Faraday's constant $\left(96,485 \mathrm{C} \mathrm{mol}^{-1}\right), A$ is the membrane surface area $\left(\mathrm{m}^{2}\right)$, and $I$ the applied current $(\mathrm{A})$.

The same formalism was used to determine the current efficiency associated to the flux of protons

$$
\eta_{\mathrm{H}^{+}}=\frac{z_{\mathrm{H}^{+}} \cdot J_{\mathrm{H}^{+}} \cdot F \cdot A}{I} \times 100 \%
$$

The carboxylic acid recovery efficiency $R_{\mathrm{e}}$ (\%) was determined as

$$
R_{\mathrm{e}}=\frac{C_{i}^{\mathrm{C}, \text { final }} \cdot V^{\mathrm{C}, \text { final }}}{C_{i}^{\mathrm{D} \text {,initial }} \cdot V^{\mathrm{D} \text {,initial }}} \times 100 \%
$$

where $C_{i}^{\text {D, initial }}$ and $C_{i}^{\mathrm{C} \text {,final }}$ are, respectively, the initial and final concentration of specie $i$ in the diluate and in the concentrate solutions $\left(\mathrm{mol} \mathrm{L}^{-1}\right), V^{\mathrm{D} \text {,initial }}$ and $V^{\mathrm{C} \text {,final }}$ are the initial and final liquid volumes of the diluate and the concentrate solutions, respectively (L).

The specific energy consumption per total carboxylate recovered $E_{\mathrm{CA}}\left(\mathrm{kW} \mathrm{h} \mathrm{kg}^{-1}\right)$ was determined as the energy demand for the transport of $1 \mathrm{~kg}$ of carboxylates to the concentrate compartment, according to the following equation

$$
E_{\mathrm{CA}}=\frac{I \cdot \int_{0}^{t} V(t) \mathrm{d} t}{\left[\left(\sum M_{i} \cdot C_{i}^{\mathrm{C}, \text { final }} \cdot V^{\mathrm{C}, \text { final }}\right)-\left(\sum M_{i} \cdot C_{i}^{\mathrm{C}, \text { initial }} \cdot V^{\mathrm{C} \text {,initial }}\right)\right]}
$$

where $I$ is the current applied during the batch extraction test (A), $V(t)$ is the resulting cell voltage imposed by the power supply unit and reported as a function of the time $t(s), M_{i}$ is the molecular weight of species $i, C_{i}^{\text {, initial }}$ and $C_{i}^{\text {C,final }}$ are, respectively, the initial and final concentrations of species $i$ in the concentrate compartment $\left(\mathrm{mol} \mathrm{L}^{-1}\right)$, while $V^{\text {C,initial }}$ and $V^{\mathrm{C}, \text { final }}$ are the initial and final liquid volumes of the concentrate solution (L).

\section{ASSOCIATED CONTENT}

\section{Supporting Information}

The Supporting Information is available free of charge at https://pubs.acs.org/doi/10.1021/acsomega.1c00397.

Ionic species measured in the diluate, concentrate, and combined anode and cathode electrolytes at the beginning and at the end of the batch extraction tests (PDF)

\section{AUTHOR INFORMATION}

\section{Corresponding Author}

Bernardino Virdis - Advanced Water Management Centre, The University of Queensland, Brisbane, Queensland 4072, Australia; $\odot$ orcid.org/0000-0001-8036-8937; Email: b.virdis@uq.edu.au

\section{Authors}

Paula Andrea Hernandez - Advanced Water Management Centre, The University of Queensland, Brisbane, Queensland 4072, Australia

Miaomiao Zhou - Shandong University, Qingdao 266237, PR China

Igor Vassilev - Faculty of Engineering and Natural Sciences, Tampere University, Tampere FI-33014, Finland; ๑ orcid.org/0000-0002-0373-5702

Stefano Freguia - Department of Chemical Engineering, Melbourne School of Engineering, The University of Melbourne, Melbourne, Victoria 3010, Australia

Yang Zhang - College of Environment and Safety Engineering, Qingdao University of Science and Technology, Qingdao 266042, China; o orcid.org/0000-0001-9096-0301

Jürg Keller - Advanced Water Management Centre, The University of Queensland, Brisbane, Queensland 4072, Australia

Pablo Ledezma - Advanced Water Management Centre, The University of Queensland, Brisbane, Queensland 4072, Australia; $\odot$ orcid.org/0000-0003-1366-639X

Complete contact information is available at:

https://pubs.acs.org/10.1021/acsomega.1c00397

\section{Notes}

The authors declare no competing financial interest.

\section{ACKNOWLEDGMENTS}

This work was funded by the Australian Research Council (ARC) through Discovery Project DP160102308 (Keller, Virdis). P.A.H. acknowledges the financial support of the Australian Government Research Training Program (RTP). P.L. acknowledges the ECR Development Fellowship from The University of Queensland. B.V. acknowledges the support of the ARC through grant FL170100086.

\section{REFERENCES}

(1) Lee, W. S.; Chua, A. S. M.; Yeoh, H. K.; Ngoh, G. C. A Review of the Production and Applications of Waste-Derived Volatile Fatty Acids. Chem. Eng. J. 2014, 235, 83-99. 
(2) Rabaey, K.; Rozendal, R. A. Microbial ElectrosynthesisRevisiting the Electrical Route for Microbial Production. Nat. Rev. Microbiol. 2010, 8, 706.

(3) Jourdin, L.; Grieger, T.; Monetti, J.; Flexer, V.; Freguia, S.; Lu, Y.; Chen, J.; Romano, M.; Wallace, G. G.; Keller, J. High Acetic Acid Production Rate Obtained by Microbial Electrosynthesis from Carbon Dioxide. Environ. Sci. Technol. 2015, 49, 13566.

(4) Ganigué, R.; Puig, S.; Batlle-Vilanova, P.; Balaguer, M. D.; Colprim, J. Microbial Electrosynthesis of Butyrate from Carbon Dioxide. Chem. Commun. 2015, 51, 3235-3238.

(5) Cavalcante, W. d. A.; Leitão, R. C.; Gehring, T. A.; Angenent, L. T.; Santaella, S. T. Anaerobic Fermentation for N-Caproic Acid Production: A Review. Process Biochem. 2017, 54, 106.

(6) Jang, Y.-S.; Kim, B.; Shin, J. H.; Choi, Y. J.; Choi, S.; Song, C. W.; Lee, J.; Park, H. G.; Lee, S. Y. Bio-Based Production of C2-C6 Platform Chemicals. Biotechnol. Bioeng. 2012, 109, 2437.

(7) Dwidar, M.; Park, J.-Y.; Mitchell, R. J.; Sang, B.-I. The Future of Butyric Acid in Industry. Sci. World J. 2012, 2012, 471417.

(8) Szwaja, S.; Naber, J. D. Combustion of N-Butanol in a SparkIgnition IC Engine. Fuel 2010, 89, 1573.

(9) Alasfour, F. N. Butanol-A Single Cylinder Engine Study: Engine Performance. Int. J. Energy Res. 1997, 21, 21-30.

(10) Moscoviz, R.; Trably, E.; Bernet, N.; Carrère, H. The Environmental Biorefinery: State-of-the-Art on the Production of Hydrogen and Value-Added Biomolecules in Mixed-Culture Fermentation. Green Chem. 2018, 20, 3159.

(11) Angenent, L. T.; Richter, H.; Buckel, W.; Spirito, C. M.; Steinbusch, K. J. J.; Plugge, C. M.; Strik, D. P. B. T. B.; Grootscholten, T. I. M.; Buisman, C. J. N.; Hamelers, H. V. M. Chain Elongation with Reactor Microbiomes: Open-Culture Biotechnology to Produce Biochemicals. Environ. Sci. Technol. 2016, 50, 2796.

(12) Kucek, L. A.; Spirito, C. M.; Angenent, L. T. High N-Caprylate Productivities and Specificities from Dilute Ethanol and Acetate: Chain Elongation with Microbiomes to Upgrade Products from Syngas Fermentation. Energy Environ. Sci. 2016, 9, 3482-3494.

(13) Agler, M. T.; Spirito, C. M.; Usack, J. G.; Werner, J. J.; Angenent, L. T. Chain Elongation with Reactor Microbiomes: Upgrading Dilute Ethanol to Medium-Chain Carboxylates. Energy Environ. Sci. 2012, 5, 8189.

(14) Spirito, C. M.; Richter, H.; Rabaey, K.; Stams, A. J.; Angenent, L. T. Chain Elongation in Anaerobic Reactor Microbiomes to Recover Resources from Waste. Curr. Opin. Biotechnol. 2014, 27, 115. (15) Prévoteau, A.; Carvajal-Arroyo, J. M.; Ganigué, R.; Rabaey, K. Microbial Electrosynthesis from CO2: Forever a Promise? Curr. Opin. Biotechnol. 2020, 62, 48-57.

(16) Xu, J.; Guzman, J. J. L.; Andersen, S. J.; Rabaey, K.; Angenent, L. T. In-Line and Selective Phase Separation of Medium-Chain Carboxylic Acids Using Membrane Electrolysis. Chem. Commun. 2015, 51, 6847.

(17) Dams, R. I.; Viana, M. B.; Guilherme, A. A.; Silva, C. M.; dos Santos, A. B.; Angenent, L. T.; Santaella, S. T.; Leitão, R. C. Production of Medium-Chain Carboxylic Acids by Anaerobic Fermentation of Glycerol Using a Bioaugmented Open Culture. Biomass Bioenergy 2018, 118, 1-7.

(18) Jourdin, L.; Winkelhorst, M.; Rawls, B.; Buisman, C. J. N.; Strik, D. P. B. T. B. Enhanced Selectivity to Butyrate and Caproate above Acetate in Continuous Bioelectrochemical Chain Elongation from $\mathrm{CO} 2$ : Steering with $\mathrm{CO} 2$ Loading Rate and Hydraulic Retention Time. Bioresour. Technol. Rep. 2019, 7, 100284.

(19) Jourdin, L.; Raes, S. M. T.; Buisman, C. J. N.; Strik, D. P. B. T. B. Critical Biofilm Growth throughout Unmodified Carbon Felts Allows Continuous Bioelectrochemical Chain Elongation from $\mathrm{CO} 2$ up to Caproate at High Current Density. Front. Energy Res. 2018, 6, 7.

(20) Vassilev, I.; Hernandez, P. A.; Batlle-Vilanova, P.; Freguia, S.; Krömer, J. O.; Keller, J.; Ledezma, P.; Virdis, B. Microbial Electrosynthesis of Isobutyric, Butyric, Caproic Acids, and Corresponding Alcohols from Carbon Dioxide. ACS Sustainable Chem. Eng. 2018, 6, 8485-8493.
(21) Van Eerten-Jansen, M. C. A. A.; Ter Heijne, A.; Grootscholten, T. I. M.; Steinbusch, K. J. J.; Sleutels, T. H. J. A.; Hamelers, H. V. M.; Buisman, C. J. N. Bioelectrochemical Production of Caproate and Caprylate from Acetate by Mixed Cultures. ACS Sustainable Chem. Eng. 2013, 1, 513.

(22) Jiang, Y.; Chu, N.; Zhang, W.; Zhang, L.; Jianxiong Zeng, R. Electro-Fermentation Regulates Mixed Culture Chain Elongation with Fresh and Acclimated Cathode. Energy Convers. Manage. 2020, 204, 112285 .

(23) Izadi, P.; Fontmorin, J.-M.; Virdis, B.; Head, I. M.; Yu, E. H. The Effect of the Polarised Cathode, Formate and Ethanol on Chain Elongation of Acetate in Microbial Electrosynthesis. Appl. Energy 2021, 283, 116310.

(24) US DOE. Breaking the Biological Barriers to Cellulosic Ethanol: A Joint Research Agenda, 2006.

(25) Woodley, J. M.; Bisschops, M.; Straathof, A. J. J.; Ottens, M. Future directions forin-situ product removal (ISPR). J. Chem. Technol. Biotechnol. 2008, 83, 121.

(26) Yousuf, A.; Bonk, F.; Bastidas-Oyanedel, J.-R.; Schmidt, J. E. Recovery of Carboxylic Acids Produced during Dark Fermentation of Food Waste by Adsorption on Amberlite IRA-67 and Activated Carbon. Bioresour. Technol. 2016, 217, 137.

(27) Bajracharya, S.; van den Burg, B.; Vanbroekhoven, K.; De Wever, H.; Buisman, C. J. N.; Pant, D.; Strik, D. P. B. T. B. In Situ Acetate Separation in Microbial Electrosynthesis from CO2 Using Ion-Exchange Resin. Electrochim. Acta 2017, 237, 267.

(28) Alkaya, E.; Kaptan, S.; Ozkan, L.; Uludag-Demirer, S.; Demirer, G. N. Recovery of Acids from Anaerobic Acidification Broth by Liquid-Liquid Extraction. Chemosphere 2009, 77, 1137.

(29) De Sitter, K.; Garcia-Gonzalez, L.; Matassa, C.; Bertin, L.; De Wever, $\mathrm{H}$. The Use of Membrane Based Reactive Extraction for the Recovery of Carboxylic Acids from Thin Stillage. Sep. Purif. Technol. 2018, 206, 177 .

(30) Wódzki, R.; Nowaczyk, J. Propionic and Acetic Acid Pertraction through a Multimembrane Hybrid System Containing TOPO or TBP. Sep. Purif. Technol. 2002, 26, 207.

(31) Jones, R. J.; Massanet-Nicolau, J.; Guwy, A.; Premier, G. C.; Dinsdale, R. M.; Reilly, M. Removal and Recovery of Inhibitory Volatile Fatty Acids from Mixed Acid Fermentations by Conventional Electrodialysis. Bioresour. Technol. 2015, 189, 279.

(32) Kim, Y. H.; Moon, S.-H. Lactic Acid Recovery from Fermentation Broth Using One-Stage Electrodialysis. J. Chem. Technol. Biotechnol. 2001, 76, 169.

(33) Andersen, S. J.; Hennebel, T.; Gildemyn, S.; Coma, M.; Desloover, J.; Berton, J.; Tsukamoto, J.; Stevens, C.; Rabaey, K. Electrolytic Membrane Extraction Enables Production of Fine Chemicals from Biorefinery Sidestreams. Environ. Sci. Technol. 2014, 48, 7135 .

(34) Vertova, A.; Aricci, G.; Rondinini, S.; Miglio, R.; Carnelli, L.; D’Olimpio, P. Electrodialytic Recovery of Light Carboxylic Acids from Industrial Aqueous Wastes. J. Appl. Electrochem. 2009, 39, 2051-2059.

(35) López-Garzón, C. S.; Straathof, A. J. J. Recovery of Carboxylic Acids Produced by Fermentation. Biotechnol. Adv. 2014, 32, 873.

(36) Huang, C.; Xu, T.; Zhang, Y.; Xue, Y.; Chen, G. Application of Electrodialysis to the Production of Organic Acids: State-of-the-Art and Recent Developments. J. Membr. Sci. 2007, 288, 1-12.

(37) Handojo, L.; Wardani, A. K.; Regina, D.; Bella, C.; Kresnowati, M. T. A. P.; Wenten, I. G. Electro-Membrane Processes for Organic Acid Recovery. RSC Adv. 2019, 9, 7854.

(38) Suwal, S.; Li, J.; Engelberth, A. S.; Huang, J.-Y. Application of Electro-Membrane Separation for Recovery of Acetic Acid in Lignocellulosic Bioethanol Production. Food Bioprod. Process. 2018, 109, 41.

(39) Du, J.; Lorenz, N.; Beitle, R. R.; Hestekin, J. A. Application of Wafer-Enhanced Electrodeionization in a Continuous Fermentation Process to Produce Butyric Acid withClostridium tyrobutyricum. Sep. Sci. Technol. 2012, 47, 43. 
(40) Chen, G. Q.; Eschbach, F. I. I.; Weeks, M.; Gras, S. L.; Kentish, S. E. Removal of Lactic Acid from Acid Whey Using Electrodialysis. Sep. Purif. Technol. 2016, 158, 230.

(41) Yu, L.; Lin, T.; Guo, Q.; Hao, J. Relation between Mass Transfer and Operation Parameters in the Electrodialysis Recovery of Acetic Acid. Desalination 2003, 154, 147.

(42) Hbová, V.; Melzoch, K.; Rychtera, M.; Sekavová, B. Electrodialysis as a Useful Technique for Lactic Acid Separation from a Model Solution and a Fermentation Broth. Desalination 2004, $162,361$.

(43) Arslan, D.; Zhang, Y.; Steinbusch, K. J. J.; Diels, L.; Hamelers, H. V. M.; Buisman, C. J. N.; De Wever, H. In-Situ Carboxylate Recovery and Simultaneous PH Control with Tailor-Configured Bipolar Membrane Electrodialysis during Continuous Mixed Culture Fermentation. Sep. Purif. Technol. 2017, 175, 27.

(44) Ramdin, M.; Morrison, A. R. T.; De Groen, M.; Van Haperen, R.; De Kler, R.; Van Den Broeke, L. J. P.; Trusler, J. P. M.; De Jong, W.; Vlugt, T. J. H. High Pressure Electrochemical Reduction of CO2to Formic Acid/Formate: A Comparison between Bipolar Membranes and Cation Exchange Membranes. Ind. Eng. Chem. Res. 2019, 58, 1834.

(45) Luo, G. S.; Wu, F. Y. Concentration of Formic Acid Solution by Electro-Electrodialysis. Sep. Sci. Technol. 2000, 35, 2485.

(46) Bélafi-Bakó, K.; Nemestóthy, N.; Gubicza, L. A Study on Applications of Membrane Techniques in Bioconversion of Fumaric Acid to L-Malic Acid. Desalination 2004, 162, 301.

(47) Yi, S. S.; Lu, Y. C.; Luo, G. S. Separation and Concentration of Lactic Acid by Electro-Electrodialysis. Sep. Purif. Technol. 2008, 60, 308.

(48) Koter, S. Separation of Weak and Strong Acids by ElectroElectrodialysis-Experiment and Theory. Sep. Purif. Technol. 2008, 60, 251.

(49) Richter, H.; Molitor, B.; Diender, M.; Sousa, D. Z.; Angenent, L. T. A Narrow PH Range Supports Butanol, Hexanol, and Octanol Production from Syngas in a Continuous Co-Culture of Clostridium Ljungdahlii and Clostridium Kluyveri with in-Line Product Extraction. Front. Microbiol. 2016, 7, 1773.

(50) Ganigué, R.; Sánchez-Paredes, P.; Bañeras, L.; Colprim, J. Low Fermentation PH Is a Trigger to Alcohol Production, but a Killer to Chain Elongation. Front. Microbiol. 2016, 7, 702.

(51) Wang, X.; Wang, Y.; Zhang, X.; Feng, H.; Xu, T. In-Situ Combination of Fermentation and Electrodialysis with Bipolar Membranes for the Production of Lactic Acid: Continuous Operation. Bioresour. Technol. 2013, 147, 442.

(52) Tanaka, Y. Ion-Exchange Membrane Electrodialysis for Saline Water Desalination and Its Application to Seawater Concentration. Ind. Eng. Chem. Res. 2011, 50, 7494-7503.

(53) Pan, X.-R.; Li, W.-W.; Huang, L.; Liu, H.-Q.; Wang, Y.-K.; Geng, Y.-K.; Kwan-Sing Lam, P.; Yu, H.-Q. Recovery of HighConcentration Volatile Fatty Acids from Wastewater Using an Acidogenesis-Electrodialysis Integrated System. Bioresour. Technol. 2018, 260, 61-67.

(54) Zhang, Y.; Angelidaki, I. Bioelectrochemical Recovery of WasteDerived Volatile Fatty Acids and Production of Hydrogen and Alkali. Water Res. 2015, 81, 188.

(55) Pan, X.-R.; Li, W.-W.; Huang, L.; Liu, H.-Q.; Wang, Y.-K.; Geng, Y.-K.; Kwan-Sing Lam, P.; Yu, H.-Q. Recovery of HighConcentration Volatile Fatty Acids from Wastewater Using an Acidogenesis-Electrodialysis Integrated System. Bioresour. Technol. 2018, 260, 61.

(56) Wang, Z.; Luo, Y.; Yu, P. Recovery of Organic Acids from Waste Salt Solutions Derived from the Manufacture of Cyclohexanone by Electrodialysis. J. Membr. Sci. 2006, 280, 134.

(57) Andersen, S. J.; Candry, P.; Basadre, T.; Khor, W. C.; Roume, H.; Hernandez-Sanabria, E.; Coma, M.; Rabaey, K. Electrolytic Extraction Drives Volatile Fatty Acid Chain Elongation through Lactic Acid and Replaces Chemical PH Control in Thin Stillage Fermentation. Biotechnol. Biofuels 2015, 8, 221.
(58) Seedorf, H.; Fricke, W. F.; Veith, B.; Brüggemann, H.; Liesegang, H.; Strittmatter, A.; Miethke, M.; Buckel, W.; Hinderberger, J.; Li, F.; Hagemeier, C.; Thauer, R. K.; Gottschalk, G. The Genome of Clostridium Kluyveri, a Strict Anaerobe with Unique Metabolic Features. Proc. Natl. Acad. Sci. U.S.A. 2008, 105, 2128.

(59) Rozendal, R. A.; Hamelers, H. V. M.; Rabaey, K.; Keller, J.; Buisman, C. J. N. Towards Practical Implementation of Bioelectrochemical Wastewater Treatment. Trends Biotechnol. 2008, 26, 450.

(60) Wainaina, S.; Parchami, M.; Mahboubi, A.; Horváth, I. S.; Taherzadeh, M. J. Food Waste-Derived Volatile Fatty Acids Platform Using an Immersed Membrane Bioreactor. Bioresour. Technol. 2019, $274,329$.

(61) Jones, R. J.; Fernández-Feito, R.; Massanet-Nicolau, J.; Dinsdale, R.; Guwy, A. Continuous Recovery and Enhanced Yields of Volatile Fatty Acids from a Continually-Fed $100 \mathrm{~L}$ Food Waste Bioreactor by Filtration and Electrodialysis. Waste Manag. 2021, 122, 81 . 


\section{University Library}

\section{- M M N E R VA A gateway to Melbourne's research publications}

Minerva Access is the Institutional Repository of The University of Melbourne

Author/s:

Hernandez, PA;Zhou, M;Vassilev, I;Freguia, S;Zhang, Y;Keller, J;Ledezma, P;Virdis, B

Title:

Selective Extraction of Medium-Chain Carboxylic Acids by Electrodialysis and Phase Separation

Date:

2021-03-12

Citation:

Hernandez, P. A., Zhou, M., Vassilev, I., Freguia, S., Zhang, Y., Keller, J., Ledezma, P. \& Virdis, B. (2021). Selective Extraction of Medium-Chain Carboxylic Acids by Electrodialysis and Phase Separation. ACS OMEGA, 6 (11), pp.7841-7850. https://doi.org/10.1021/ acsomega.1c00397.

Persistent Link:

http://hdl.handle.net/11343/277924

License:

CC BY-NC-ND 